Pak. j. sci. ind. res. Ser. A: phys. sci. 201356 (1) 47-53

\title{
Comparative Study of D-Slot and Straight Slot in Compact Spinning System under Mechanical Variables
}

\author{
Nasir Mahmood ${ }^{\text {a*}}$, Muhammad Qamar Tusief ${ }^{\text {a }}$, Ghulam Murtaza ${ }^{\text {a }}$, Rashid Kanwar ${ }^{\mathrm{b}}$ \\ and Mahmood Ahmed Khan \\ ${ }^{a}$ Department of Fibre \& Textile Technology, Universiy of Agriculture Faisalabad, Faisalabad, Pakistan \\ ${ }^{b}$ Department of Physics, University of Agriculture Faisalabad, Faisalabad, Pakistan \\ 'Department of Math and Statistics, University of Agriculture Faisalabad, Faisalabad, Pakistan
}

(received October 31, 2011; revised September 5, 2012; accepted September 12, 2012)

\begin{abstract}
The present research study was planned, to appraise the quality and properties of the compact yarn as influenced by hank roving, type of suction slots, spindle speed and spacer size. The basic properties of the compact yarn such as strength, elongation, unevenness and hairiness were analyzed as a function of compact spinning to control those protruding fibres which become the part of the yarn but have no role in the yarn formation and ultimately no contribution to yarn strength.
\end{abstract}

Keywords: suction straight and D slots, spindle speed, hank roving, spacers

\section{Introduction}

Although the first industrial compact spinning frame was launched at ITMA (International Textile Market Association) in 1995, yet investigations on compact yarns were carried out since 1993. It is generally known that the compact spinning method is certainly an excellent substitute for conventional yarn spinning, since it minimizes the hairiness of single yarns. This can reduce the twisting angle and develop yarn quality. The properties of compact yarn are better than conventional ring spun yarn. Compact spinning gives the potential to generate a near-perfect yarn structure by applying air suction to compact the fibre stream in the main drafting zone, thereby virtually reducing the spinning triangle. There are many new schemes offered to deal with the present yarn quality/production speed difficulty on traditional ring systems and compact yarn spinning is one of these schemes. Although this system uses the main components of a traditional ring spinning system, it is also considered to be a new spinning system by some researchers (Tyagi and Kumar, 2009). The compact spinning systems are mostly used for spinning of combed yarn, however, many attempts have been made to use the compact system for spinning carded yarns. Recently, D-type slot compact system has been introduced for producing carded compact yarn. D-slot has more slot length than straight slot. In straight slot compacting system, the compactness is achieved by fibre transport through the perforated lattice and air drawn through inclined slots in compact spinning system.

*Author for correspondence

E-mail: nasirmahmood23uaf@yahoo.com
D-slot has delta shape at the entry point which helps the shorter fibres to compact in a better manner, resulting in better utilization of short fibres. In compact spinning, tension differences between fibres during the twist insertion are smaller than those in ring spinning due to the elimination of the spinning triangle (Loganathan et al., 2009).

The pressure between the aprons in the drafting zone is controlled by spinning spacer; in turn it governs the degree of control exercised on the floating fibres and as such would have influence over the drafting irregularities. It is often necessary to use a wider spacer for a coarser count however, if there are un drafted places in the yarn when it leaves the front rollers, the break draft should be increased. Spacer should be increased only if the draft results remain unsatisfactory after the break draft has been increased (Kumar et al., 2006). The drafting quality at the compact frames is governed by apron spacing and twist in the input roving. The yarn quality is also affected by the input hank roving. Control over the fibres in top arm drafting is critically influenced by the apron spacing. Reduction of apron spacing improves the control over the fibres, but settings below a certain level lead to frequent drafting faults and therefore to more irregular yarn. Apron spacing influence upon the yarn imperfection, count upon yarn evenness. Optimum apron spacing is dependent upon top-roller loading and lies at a lower level at higher load. Apron spacing has also a significant effect on the nep count in the yarn, closer spacing leading to less neps. 
The D-slot has more length than conventional slot with delta shape entry point which helps the shorter fibre to compact in a better manner that results in good short fibre utilization as shown in Fig. 1a-c (Loganathan et al., 2009). As apron spacing is closed down with hard twisted roving, the improvements obtained from better fibre control are offset by the increased incidence of drafting faults; therefore, the resultant yarn does not show any improvement in regularity. However, regularity improves with closer apron spacing in the case of soft twisted roving (Balasubramanian, 1975). The industry is moving rapidly towards higher spindle speeds, it is important to find out the important properties that affect end breakage of yarn. Spindle speed is one of the important factors which affect the yarn properties, i.e., tensile strength, mass irregularity, imperfections and yarn hairiness. With the increase in spindle speed, there is an increasing trend of yarn tenacity. As the spindle speed increases, the randomization of the fibres in the yarn gradually increases which causes better paralleli-
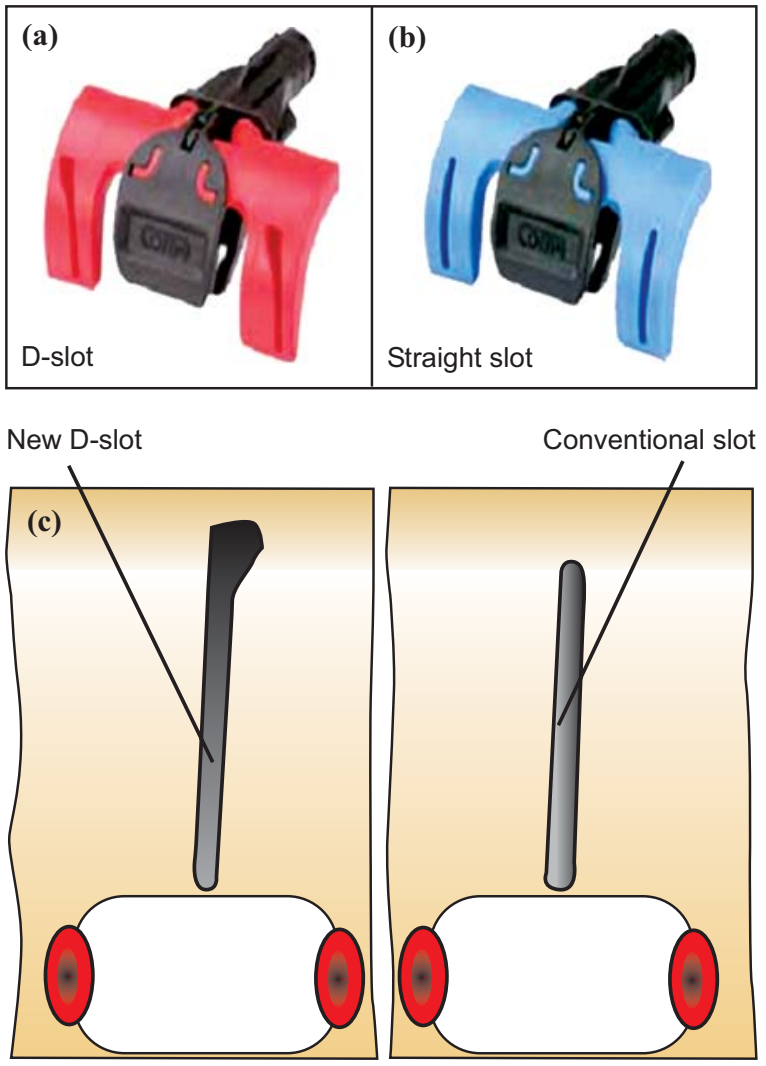

Fig. 1a-c. Slots for compact spinning (a) D-slot; (b) straight slot and (c) schematic D-slot and conventional s-slot. zation of fibres along the axis in the yarn and hence increases the load shearing capacity of the fibres. At higher spindle speed, packing coefficient is higher resulting higher compactness. Higher the compactness of the yarn structure; better is the fibre migration within the yarn and hence, higher is the interlocking structure of fibres within the yarn (Chaudhuri, 2003).

\section{Materials and Methods}

The present research work was conducted in the Department of Fibre and Textile Technology, University of Agriculture, Faisalabad and a Textile Mill at Faisalabad. Thirty six (36) yarn samples were prepared to spin the $40, \mathrm{~s}$ yarn count. The following Trailed variables were selected for this research work (Table 1).

Yarn characteristics. All the yarn samples prepared were subjected to test the following characteristics by using standard techniques.

Yarn lea strength (lbs). Lea strength of yarn was determined in pounds according to the ASTM standards (2008). A pendulum type lea strength-testing machine was used to test the strength of yarn. This machine gives the direct reading for lea strength.

Count lea strength product (CLSP). Count lea strength product value was determined by multiplying actual count value with the respective lea strength value of yarn $($ CLSP $=$ Yarn Count $\times$ Lea Strength $)$ according to British standards (1985).

Tensile properties of yarn. Tensile properties i.e. single yarn strength, elongation and rupture per kilometer were observed with Uster Tenso-jet which works on the principle of constant rate of extension (CRE). The principle describes the fact that the moving clamps are displaced at constant velocity as a result of which the specimen caught in between the stationary and moving clamps extended by a constant rate. The breaking tenacity was measured from the maximum force which was applied anywhere between the beginning of the

Table 1. Trailed variables

\begin{tabular}{llll}
\hline \hline Slots & $\begin{array}{l}\text { Spindle speed } \\
\text { ' } \mathrm{T} \text { ' }\end{array}$ & $\begin{array}{l}\text { Hank roving } \\
\text { ' } \mathrm{rpm} \text { ' }\end{array}$ & $\begin{array}{l}\text { Spacer } \\
\text { 'P' }(\mathrm{mm})\end{array}$ \\
\hline $\mathrm{T}_{1}=$ D-Slot & $\mathrm{S}_{1}=18000$ & $\mathrm{H}_{1}=1.0$ & $\mathrm{P}_{1}=3.00$ \\
$\mathrm{~T}_{2}=$ Straight slot & $\mathrm{S}_{2}=20000$ & $\mathrm{H}_{2}=1.2$ & $\mathrm{P}_{2}=3.25$ \\
& $\mathrm{~S}_{3}=22000$ & $\mathrm{H}_{3}=1.4$ & \\
\hline
\end{tabular}


test and the final rupture of the specimen. The breaking elongation of yarn was measured from the clamp displacement at the point of peak force. The procedure was described in the ASTM standard (2008).

Analysis of data. Factorial design was applied in the analysis of variance of data for testing the differences among various quality characteristics as suggested by Montgomery (2009) using statistical package for social science (SPSS) micro computer statistical programme.

\section{Results and Discussion}

Yarn lea strength. The statistical analysis of variance and comparison of individual means for yarn lea strength are shown in Table 2. The results indicate that the effect of slots, spacers, spindle speed and hank roving are highly significant for yarn lea strength whereas, all the interactions were non-significant.

Duncan's multiple range test showed that the mean values of yarn lea strength were 66.592 and 65.836 pound with $\mathrm{T}_{1}$ (D-slot) and $\mathrm{T}_{2}$ (Straight slot), respectively. These values were significant from each other. The value of yarn lea strength for D-slot system was more than that of straight slot system. D-slot compact spinning system improved yarn tensile properties as compared to conventional spun yarn. These results match with the previous findings that compact spinning improved the tensile properties of the yarn and strength of the compact yarns was increased up to approximately 20\% (Loganathan and Lakshmikantha 2009a, Ozdil et al., 2005).

In case of different spindle speeds, values of yarn lea strength were $67.521,66.194$ and 64.927 pounds for
$\mathrm{S}_{1}$ (18000), $\mathrm{S}_{2}$ (20000) and $\mathrm{S}_{3}$ (22000), respectively. This showed that higher spindle speed reduced yarn lea strength values. It is because the spindle speed has direct correlation with the strength parameters (El-Sayed, 2009).The mean values of yarn lea strength at different levels of hank roving $\mathrm{H}_{1}, \mathrm{H}_{2}$ and $\mathrm{H}_{3}$ were 65.402, 66.223 and $67.017 \mathrm{lbs}$, respectively. It indicated that $\mathrm{H}_{1}, \mathrm{H}_{2}$ and $\mathrm{H}_{3}$ differed significantly from each other. Finer hank roving increased the yarn lea strength, and effect of hank roving was highly significant on yarn lea strength. These results are in line with the findings of Shahbaz et al. (2003) that coarser hank roving produced weaker yarn and fine hank roving produced stronger yarn.

In case of different spacers, the values of yarn lea strength were 66.803 and 65.626 pounds for $P_{1}(3 \mathrm{~mm})$ and $\mathrm{P}_{2}(3.25 \mathrm{~mm})$, respectively. It is evident from the results that smaller spacer increased the yarn lea strength values. The results get support from the findings that spacer size has significant effect on yarn strength and with increase in spacer size the yarn lea strength decreased (Kumar et al., 2006).

Yarn count lea strength product. The statistical analysis of variance and comparison of individual means for count lea strength product are shown in Table 3. The results indicated that the effect of slots, spacers, spindle speed and hank roving were highly significant upon yarn lea strength. All the interactions were non-significant for this parameter.

Duncan's multiple range test showed that in case of different suction slots i.e. $\mathrm{T}_{1}$ (D-slot) and $\mathrm{T}_{2}$ (Straight slot) the mean values of yarn count lea strength product

Table 2. Comparison of individual treatment means for yarn lea strength (Lbs)

\begin{tabular}{llllllll}
\hline \hline Slots & Means & Spindle speed & Means $(\mathrm{rpm})$ & Hank roving & Means & Spacer & Means (mm) \\
\hline $\mathrm{T}_{1}$ & $66.592 \mathrm{a}$ & $\mathrm{S}_{1}$ & $67.521^{\mathrm{a}}$ & $\mathrm{H}_{1}$ & $65.402^{\mathrm{a}}$ & $\mathrm{P}_{1}$ & $66.803^{\mathrm{a}}$ \\
$\mathrm{T}_{2}$ & $65.836 \mathrm{~b}$ & $\mathrm{~S}_{2}$ & $66.194^{\mathrm{b}}$ & $\mathrm{H}_{2}$ & $66.223^{\mathrm{b}}$ & $\mathrm{P}_{2}$ & $65.626^{\mathrm{b}}$ \\
- & - & $\mathrm{S}_{3}$ & $64.927^{\mathrm{c}}$ & $\mathrm{H}_{3}$ & $67.017^{\mathrm{c}}$ & - & - \\
\hline \hline
\end{tabular}

Mean values having different letters differ significantly at 5\% level of significance

Table 3. Comparison of individual treatment means for count lea strength product (CLSP)

\begin{tabular}{|c|c|c|c|c|c|c|c|}
\hline Slots & Means & Spindle speed & Means (rpm) & Hank roving & Means & Spacers & Means (mm) \\
\hline$T_{1}$ & $2702.8 \mathrm{a}$ & $\mathrm{S}_{1}$ & $2740.9^{\mathrm{a}}$ & $\mathrm{H}_{1}$ & $2652.2^{\mathrm{c}}$ & $P_{1}$ & $2711.3^{\mathrm{a}}$ \\
\hline $\mathrm{T}_{2}$ & $2669.9 b$ & $\mathrm{~S}_{2}$ & $2684.7^{b}$ & $\mathrm{H}_{2}$ & $2686.3^{\mathrm{b}}$ & $\mathrm{P}_{2}$ & $2661.4^{b}$ \\
\hline- & - & $\mathrm{S}_{3}$ & $2633.4^{c}$ & $\mathrm{H}_{3}$ & $2720.5^{\mathrm{a}}$ & - & - \\
\hline
\end{tabular}

Mean values having different letters differ significantly at $5 \%$ level of significance 
were 2702.8 and 2669.9 hanks, respectively. These values had highly significant difference from each other. It can be concluded that for D-slot system the value of yarn lea strength product is more than that of straight slot system. In case of different spindle speeds the values of yarn lea strength product were $2740.9,2684.7$ and 2633.4 hanks for $\mathrm{S}_{1}(18000), \mathrm{S}_{2}$ (20000) and $S_{3}(22000)$, respectively. Higher spindle speed reduced yarn lea strength product values, and change in spindle speed produced a significant change on yarn strength, evenness and imperfections (Kumar, 2007).

The mean values of yarn lea strength product at different levels of hank roving $\mathrm{H}_{1}, \mathrm{H}_{2}$ and $\mathrm{H}_{3}$ as shown in Table 3 were 2652.2, 2686.3 and 2720.5 hanks, respectively. $\mathrm{H}_{1}, \mathrm{H}_{2}$ and $\mathrm{H}_{3}$ had significant difference from each other. It can therefore, be stated that finer hank roving increased the yarn lea strength, and hank roving has direct effect on yarn strength and tensile properties, and draft ratio calculated with the help of roving count decreased with decrease in roving count (Ureyen and Kadoðlu, 2007; Shahbaz et al., 2003). In case of different spacer, the values of yarn lea strength product were found as 2711.3 and 2661.4 hanks for $\mathrm{P}_{1}$ (3 $\mathrm{mm})$ and $\mathrm{P}_{2}(3.25 \mathrm{~mm})$, respectively. It is evident from the results that smaller spacer increased the yarn lea strength product values. These results got support from the findings of Kumar et al. (2006) that spacer size had significant effect on yarn strength and with increase in spacer size the yarn count lea strength product decreased. Increase of apron spacing decreased apron strength of yarn and largely depended upon the yarn lea strength (Mahmood, 1995).

Yarn single end strength (g/tex). The statistical analysis of variance and comparison of individual means for yarn single end strength are presented in Table 4 . The results indicated that the effect slots, spacers, spindle speed and hank roving were highly significant for yarn lea strength. In case of interactions, all the interactions remained non-significant.
Duncan's multiple range test showed that in case of different suction slots i.e. $T_{1}$ (D-slot) and $T_{2}$ (Straight slot) the mean values of yarn single end strength were 251.72 and $248.86 \mathrm{~g}$, respectively. These values were significantly different from each other. It can be concluded that for D-slot system the value of yarn single end strength is more than that of straight slot system. These results are correlated with the findings of Loganathan and Lakshmikantha (2009) that the yarn spun at D-slot compact spinning system exhibited improvement in yarn tensile properties of yarn, as compact yarns hold little hairiness, improved strength, better uniformity and lesser values of thick and thin places and neps. This is the main cause for improved yarn strength and reduced creation of fluff. Moreover, during compact spinning process the spinning triangle is reduced and arrangements of fibres in the yarn are found better (Kane et al., 2007; Celik and Kadoglu, 2004). In case of different spindle speeds the values of yarn single end strength were 255.23, 250.21 and $245.43 \mathrm{~g}$ for $\mathrm{S}_{1}(18000), \mathrm{S}_{2}(20000)$ and $\mathrm{S}_{3}(22000)$, respectively. Higher spindle speed reduced yarn single end strength values. The results are at par with the findings of Usta (2008) that spindle speed influence the significant effect on yarn strength and further mentioned that yarn strength increased with decrease in spindle speed.

Mean values of yarn single end strength at different levels of hank roving $\mathrm{H}_{1}, \mathrm{H}_{2}$ and $\mathrm{H}_{3}$ as shown in the Table 4 were 247.22, 250.32 and 253.33 g, respectively. It indicated that, $\mathrm{H}_{1}, \mathrm{H}_{2}$ and $\mathrm{H}_{3}$ had significant differences from each other. Finer hank roving increased the yarn single end strength. These results match with the research work by Shahbaz et al. (2003). There was significant effect of hank roving on yarn strength and fine hank roving produced stronger yarn as compared to coarser hank roving. In case of different spacer the values of yarn single end strength were found as 252.51 and $248.06 \mathrm{~g}$ for $\mathrm{P}_{1}(3 \mathrm{~mm})$ and $\mathrm{P}_{2}(3.25 \mathrm{~mm})$, respectively. Smaller spacer increased the yarn single end strength values.

Table 4. Comparison of individual treatment means for yarn single end strength (g)

\begin{tabular}{|c|c|c|c|c|c|c|c|}
\hline Slots & Means & Spindle speed & Means (rpm) & Hank roving & Means & Spacer & Means (mm) \\
\hline $\mathrm{T}_{1}$ & $251.72 \mathrm{a}$ & $\mathrm{S}_{1}$ & $255.23^{\mathrm{a}}$ & $\mathrm{H}_{1}$ & $247.22^{\mathrm{c}}$ & $P_{1}$ & $252.51^{\mathrm{a}}$ \\
\hline $\mathrm{T}_{2}$ & $248.86 b$ & $\mathrm{~S}_{2}$ & $250.21^{b}$ & $\mathrm{H}_{2}$ & $250.32^{\mathrm{b}}$ & $\mathrm{P}_{2}$ & $248.06^{\mathrm{b}}$ \\
\hline- & - & $\mathrm{S}_{3}$ & $245.43^{c}$ & $\mathrm{H}_{3}$ & $253.33^{\mathrm{a}}$ & - & - \\
\hline
\end{tabular}

Mean values having different letters differ significantly at $5 \%$ level of significance 
Yarn breaking length (g/tex). The statistical analysis of variance and comparison of individual means for yarn breaking length are given in Table 5. The results indicated that the effect slots, spacers and hank roving had highly significant effect on yarn breaking length but spindle speed had significant effect on yarn rupture per kilometer whereas, all the interactions were non-significant.

Duncan's multiple range test showed that in case of different suction slots i.e. $\mathrm{T}_{1}$ (D-slot) and $\mathrm{T}_{2}$ (Straight slot) the mean values of yarn breaking length were 17.297 and $17.087 \mathrm{~g} /$ tex, respectively. These values had significant difference from each other. It can be concluded that for D-slot system the value of yarn rupture per kilometer is more than that of straight slot system. The present results are agreed with the findings of Loganathan and Lakshmikantha (2009a) who stated that the yarn spun at D-slot compact spinning system generated more flexible and better results. Likewise Celik and Kadoglu (2004) indicated that the compact yarns held little hairiness, improved strength, better uniformity and lesser values of thick and thin places and neps compared to the conventional ring-spun yarn and with their improved yarn strength and reduced creation of fluff. Kane et al. (2007) had also mentioned that in compact spinning process the spinning triangle was reduced and arrangement of fibres in the yarn was better than ring spun yarn. When compact yarn properties were compared with conventional ring yarn, the strength of compact yarn was higher up to $15-20 \%$ and elongation by nearly $20 \%$ and hairiness was less as much as $50 \%$.

In case of different spindle speeds the values of yarn breaking length were $17.542,17.181$ and $16.853 \mathrm{~g} /$ tex for $S_{1}(18000), S_{2}(20000)$ and $S_{3}(22000)$, respectively. It is evident from the results that higher spindle speed reduced yarn breaking length. Lawal et al. (2011) also concluded that the tenacity of flax/cotton blended yarns decreased with increase of spindle speed. Likewise, El-Sayed (2009) discussed that the spindle speed had small effect on yarn elongation and tenacity.

The mean values of yarn breaking length at different levels of hank roving $\mathrm{H}_{1}, \mathrm{H}_{2}$ and $\mathrm{H}_{3}$ as shown in the Table 5 were $16.973,17.192$ and $17.411 \mathrm{~g} /$ tex, respectively. It indicated that $\mathrm{H}_{1}, \mathrm{H}_{2}$ and $\mathrm{H}_{3}$ had highly significant differences from each other. In case of different spacer the values of yarn breaking length were found as 17.353 and $17.031 \mathrm{~g} /$ tex for $P_{1}(3 \mathrm{~mm})$ and $P_{2}$ $(3.25 \mathrm{~mm})$, respectively. It is evident from the results that smaller spacer increased the yarn breaking length values.

Yarn elongation (\%). The statistical analysis of variance and comparison of individual means for yarn elongation are shown in Table 6 . The results indicated that the effect slots, spacer and hank roving were highly significant for yarn elongation percentage but spindle speed had significant effect on yarn elongation percentage. In case of interactions, all the interactions remained non-significant.

Duncan's multiple range test showed that in case of different suction slots i.e. $\mathrm{T}_{1}\left(\mathrm{D}\right.$-slot) and $\mathrm{T}_{2}$ (Straight slot) the mean values of yarn elongation percentage were 6.809 and $6.727 \%$, respectively. These values differed significantly from one another. It can be concluded that for D-slot system the value of yarn elongation percentage is more than that of straight slot

Table 5. Comparison of individual treatment means for yarn breaking length

\begin{tabular}{|c|c|c|c|c|c|c|c|}
\hline Slots & Means & Spindle speed & Means (rpm) & Hank roving & Means & Spacers & Means (mm) \\
\hline $\mathrm{T}_{1}$ & $17.297 \mathrm{a}$ & $\mathrm{S}_{1}$ & $17.542^{\mathrm{a}}$ & $\mathrm{H}_{1}$ & $16.973^{c}$ & $\mathrm{P}_{1}$ & $17.353^{\mathrm{a}}$ \\
\hline $\mathrm{T}_{2}$ & $17.087 \mathrm{~b}$ & $\mathrm{~S}_{2}$ & $17.181^{b}$ & $\mathrm{H}_{2}$ & $17.192^{b}$ & $\mathrm{P}_{2}$ & $17.031^{b}$ \\
\hline- & - & $\mathrm{S}_{3}$ & $16.853^{\mathrm{c}}$ & $\mathrm{H}_{3}$ & $17.411^{\mathrm{a}}$ & - & - \\
\hline
\end{tabular}

Mean values having different letters differ significantly at $5 \%$ level of significance

Table 6. Comparison of individual treatment means for yarn elongation (\%)

\begin{tabular}{llllllll}
\hline \hline Slots & Means & Spindle speed & Means $(\mathrm{rpm})$ & Hank roving & Means & Spacer & Means $(\mathrm{mm})$ \\
\hline $\mathrm{T}_{1}$ & $6.809 \mathrm{a}$ & $\mathrm{S}_{1}$ & $6.904^{\mathrm{a}}$ & $\mathrm{H}_{1}$ & $6.682^{\mathrm{c}}$ & $\mathrm{P}_{1}$ & $6.832^{\mathrm{a}}$ \\
$\mathrm{T}_{2}$ & $6.727 \mathrm{~b}$ & $\mathrm{~S}_{2}$ & $6.764^{\mathrm{b}}$ & $\mathrm{H}_{2}$ & $6.768^{\mathrm{b}}$ & $\mathrm{P}_{2}$ & $6.704^{\mathrm{b}}$ \\
- & - & $\mathrm{S}_{3}$ & $6.636^{\mathrm{c}}$ & $\mathrm{H}_{3}$ & $6.854^{\mathrm{a}}$ & - & - \\
\hline \hline
\end{tabular}

Mean values having different letters differ significantly at $5 \%$ level of significance 
system. These results are correlated with research work of Almetwally and Salem (2010) that there was main difference between ring and compact yarn. The strength and elongation of compact yarn were higher than conventional ring spun yarn and lower value of hairiness. Moreover, Tyagi et al. (2010) reported that, the increased elongation in the compact yarn as compared to the ring spun yarn was due to better arrangement of fibres in the body of the yarn resulting in improved elongation and strength of the compact yarns.

In case of different spindle speeds the values of yarn elongation were found as $6.904,6.764$ and $6.636 \%$ for $\mathrm{S}_{1}$ (18000), $\mathrm{S}_{2}(20000)$ and $\mathrm{S}_{3}(22000)$, respectively. It is evident from the results that higher spindle speed reduced yarn elongation percentage gradually. These results agreed with the findings of El-Sayed (2009) who discussed that the spindle speed had small effect on yarn elongation and tenacity. Moreover, Usta (2008) mentioned that with the increase in spindle speed and balloon angle caused an increase in the breaking elongation of the yarn.

The mean values of yarn elongation percentage at different levels of hank roving $\mathrm{H}_{1}, \mathrm{H}_{2}$ and $\mathrm{H}_{3}$ as shown in Table 6 were 6.682, 6.768 and $6.854 \%$, respectively. It indicates that $\mathrm{H}_{1}, \mathrm{H}_{2}$ and $\mathrm{H}_{3}$ differed significantly from each other. The increase in roving yarn count increased the yarn elongation percentage. These results are in line with the findings of Ureyen and Kadoolu (2007), that draft ratio calculated with the help of roving count on ring spinning and yarn elongation decreased with the decrease in roving count and increased the hank roving increase elongation. In case of different spacer the values of yarn elongation percentage were found as 6.832 and $6.704 \%$ for $\mathrm{P}_{1}(3 \mathrm{~mm})$ and $\mathrm{P}_{2}$ $(3.25 \mathrm{~mm})$, respectively. It is evident from the results that smaller spacer increased the yarn elongation percentage.

\section{Conclusion}

The D-slot produced better results as compared to the straight slot with the advantages of greater yarn quality. The D-slot improved yarn strength and minimum value of irregularity $(\mathrm{U} \%)$. Better spinning performance and ultimate yarn quality was achieved by lower spindle speed $(18000 \mathrm{rpm})$. The minimum value of spindle speed $\mathrm{S}_{1}(18000 \mathrm{rpm})$ produced better results for the tensile properties of yarn. The best yarn quality was obtained by using thinner spacer i.e. $\left(\mathrm{P}_{1}=3.00 \mathrm{~mm}\right)$ as compared to wider spacers i.e. $\left(\mathrm{P}_{2}=3.25 \mathrm{~mm}\right)$. The thinner spacer $\left(\mathrm{P}_{1}=3.00 \mathrm{~mm}\right)$ improved the yarn strength, imperfection and reduced the hairiness of yarn. Finer hank roving increased the tensile properties of yarn.

\section{References}

Almetwally, A.A., Salem, M.M. 2010. Comparison between mechanical properties of fabrics woven from compact and ring spun yarns. AUTEX Research Journal, 10: 35-40.

ASTM Committee. 2008. Standard Test Method for Measurement of Yarn. ASTM Designation D:190707, D:1578-93, D:2256-02, D:6197-99. American Society for Testing and Materials, Philadelphia, USA.

Balasubramanian, N. 1975. The effect of top roller weighting, apron spacing, and top roller setting upon yarn quality. Textile Research Journal, 45: 322-325.

British Standard. 1985. Determination of Lea Strength Lea Product of Spun Yarn Count. Methods of Test for Textiles. British Standards Hand Book-II. pp. 141-142, British Standards Institute London, UK.

Celik, P., Kadoðlu, H. 2004. A research on the compact spinning for long staple yarns. Fibres \& Textiles in Eastern Europe, 12: 27-31.

Chaudhuri, A. 2003. Effect of spindle speed on the properties of ring spun acrylic yarn. Journal of Institution of Engineers (India), 84: 10-13.

El-Sayed, M.A.M. 2009. Optimizing ring spinning variables and a proposed procedure to determine the Egyptian cotton spinning potential. Journal of Textile Apparel Technology and Management, 6: 1-9.

Kane, D.C., Patil, U.J., Sudhakar, P. 2007. Studies on the influence of knit structure and stitch length on ring and compact yarn single jersey fabric properties. Textile Research Journal, 77: 572-582.

Kumar, B.K., Kumar, R.V. , Thilagavathi, G. 2006. Effect of spacers \& shore hardness on yarn quality. Indian Textile Journal, 117: 50-52.

Kumar, R.M. 2007. Yarn quality depends upon the settings and spindle speeds. Journal of the Textile Association, 67: 225-226.

Lawal, A.S., Nkeonye, P.O., Anandjiwala, R.D. 2011. Influence of spindle speed on yarn quality of flax/cotton blend. The Open Textile Journal, 4: $7-12$. 
Loganathan, R., Lakshmikantha, C.B. 2009a. Mechanical properties and fault analysis of D-slot carded compact yarn. Indian Journal of Fibre \& Textile Research, 34: 225-230.

Loganathan, R., Mallyah, M., Ramachandran, T. 2009b. Influence of D-type slot compact system on migration properties of the carded compact yarn. Journal of Engineered Fibers and Fabrics, 4: 7-13.

Mahmood, H.T. 1995. Effect of hank roving twist, break draft and apron spacing at ring frame on double rove yarn spinning. M.Sc. Thesis. pp. 60-111, Department of Fibre and Textile Technology, University of Agriculture, Faisalabad, Pakistan.

Montgomery, D.C. 2009. Design and Analysis of Experiments, $7^{\text {th }}$ edition, John Willy and Sons. Arizona State University, USA.

Ozdil, N., Ozdoðan, E., Demirel, A., Oktem, T. 2005. A comparative study of the characteristics of compact yarn-based knitted fabrics. Fibres and Textiles in Eastern Europe Eur., 13: 39-43.

Shahbaz, B.S., Nawaz, M., Farooq, A., Mukhtar, A.
2003. Effect of different hank rovings on spinability of cotton yarn of different counts [online] available at http://www.ptj.com. pk/Web\%202003/4-2003/ files/art-babar.htm. Verified on (22-6-2011).

Tyagi, G.K., Bhowmick, M., Bhattacharyya, S., Kumar, R. 2010. Effect of spinning conditions on mechanical and performance characteristics of cotton-ring and compact-spun yarns. Indian Journal of Fibre \& Textile Research, 35: 21-30.

Tyagi, G.K., Kumar, R. 2009. Influence of spinning variables on migration parameters of compact and ring-spun yarns. Indian Journal of Fibre \& Textile Research, 34: 333-337.

Ureyen E.M., Kadoðlu, H. 2007. The prediction of cotton ring yarn properties from AFIS fibre properties by using linear regression models. Fibres and Textiles in Eastern Europe, 15: 63-67.

Usta, Y. 2008. Effect of balloon angle on the hairiness and other yarn properties of polyester ring spun yarn. Fibres and Textiles in Eastern Europe, 16: 40-47. 